\title{
IN VITRO ASSESSMENT OF THE BIOLOGICAL ACTIVITY OF A NEW REGENERATIVE AGENT PREPARED FROM THE CONCENTRATE OF DEPROTEINIZED DERMAL LAYER OF PORCINE SKIN
}

\author{
Natalia Bezdieniezhnykh \\ beznaliano@gmail.com \\ Aleksandra Lykhova ${ }^{1}$ \\ AlexxDNA@gmail.com \\ Hennadii Borschevskyi \\ Department of Biotechnology (Pharmaceutical Development Laboratory) ${ }^{2}$ \\ m.bor@ukr.net \\ Kateryna Dyakun \\ Department of Biotechnology $y^{2}$ \\ k.dyakun@farmak.ua \\ Ievgen Kruglov \\ Department of $R \& D^{2}$ \\ i.kruglov@farmak.ua \\ ${ }^{1}$ Department of Laboratory of Model Systems of Experimental Oncology \\ R.E. Kavetsky Institute of Experimental Pathology, Oncology and Radiobiology of National \\ Academy of Sciences of Ukraine \\ 45 Vasilkivska str., Kyiv, Ukraine, 03022 \\ ${ }^{2} J S C$ «Farmak» \\ 63 Kyrylivska str., Kyiv, Ukraine, 04080
}

\begin{abstract}
Background. Presently, a prospective direction for the development of regenerative medicine in the world is the search for regulatory molecules and the identification of molecular targets to stimulate the body's endogenous regenerative potential. The concentrate of the deproteinized dermal layer of porcine skin (CDDLPS) is a new therapeutic agent with restorative properties, the action of which is directed on the induction of the self resources of cells. Aim. The assessment of the effect of CDDLPS on the proliferative activity of mammalian cells of different histogenesis in vitro.

Materials and Methods. To determine the amino acid composition of the CDDLPS liquid chromatography and biochemical methods were used. The biological effects and mechanisms of action of the drug were investigated by cell culture and molecular biological methods. The research was carried out using stable cell lines: human keratinocytes (HaCaT cell line), porcine endothelial cells (PAE cell line), bovine kidney cells (MDBK cell line) and mouse fibroblasts (3T3A31 cell line).

Results. The cells of the bovine kidney MDBK cell line were the most sensitive to the effect of the CDDLPS. Also, the obtained results suggest that, depending on the concentration, the drug not only stimulates cell proliferation by $10-30 \%$, but also significantly enhances biosynthetic processes in cells, in particular, protein synthesis by $20-40 \%$. Conclusions. CDDLPS is an effective and affordable therapeutic agent with restorative properties, the biological activity of which manifests itself in the activation of cell biosynthetic and proliferative potentials and is comparable to effects of some growth factors, in particular epidermal growth factor.
\end{abstract}

Keywords: regeneration, proliferation, protein synthesis, concentrate of deproteinized dermal layer of porcine skin.

DOI: $10.21303 / 2504-5695.2020 .001534$

\section{Introduction}

Despite the large number of different methods and means of regenerative therapy, aimed at healing, repairing the skin after the trauma or the elimination of defects of another nature, the 
development of new approaches to the treatment of such pathology remains an urgent clinical problem. Because a long time is usually spent on the treatment of the wound, rather than restoration of the skin integrity, it often leads to aesthetic and functional problems due to the formation of scar tissue [1]. In addition, skin wounds can cause significant damage to adjacent tissues, which impairs the homeostatic mechanisms of the body, involved in spontaneous healing. To achieve complete reconstruction of the damaged area, these events include the induction of inflammation on the one hand and tissue remodeling on the other. Restoration of skin integrity in adults usually occurs via fibrosis, which leads to the appearance of a scar, which is not as plastic as intact skin, because it consists of elements of the extracellular matrix [2]. Therefore, it is extremely important today to develop the means of tissue regeneration, including those stimulating the self-restoration of skin. Among them, one should mention the epidermal growth factor (EGF), which is involved in the healing of skin wounds by stimulating the proliferation and migration of keratinocytes, endothelial cells and fibroblasts [3]. Clinical trials have shown that topical administration of EGF increases epithelialization and reduces the healing time of skin grafts, venous ulcers and diabetic foot ulcers. However, EGF is known to play an important role in the development of cancer that significantly complicates its therapeutic use, especially today when the issue of oncological safety of substances is extremely important [4-6]. That is why this study evaluated a new potential regenerative drug, namely the concentrate of the deproteinized dermal layer of porcine skin (CDDLPS), which may become an adequate and affordable remedy with restorative properties. According to the safety assessment of the medicinal product, this concentrate was safe and successfully passed preclinical testing and screening studies of the wound healing effect in the form of a spray; also, clinical trials of this medicine have assessed the efficacy and tolerability of the drug in patients with stage II burns. According to the results of the clinical study, the efficacy of treatment in the group of patients with the use of the experimental drug against the background of baseline therapy was proved to be higher in comparison with the control group of patients, receiving only basic therapy. Based on the results of clinical studies, the medicinal product CDDLPS, produced by JSC «Farmak», was recommended for medical use, ie the treatment of patients with burns. That is why the aim of our study was to search for a sensitive cell model to study the mechanisms of action of the test CDDLPS in vitro and to develop a protocol for regular testing of its biological activity.

Today, it remains relevant to search for ways to actively influence the recovery processes, i.e. creation of optimal conditions for the regeneration of damaged organs and tissues. Our results will allow us to study the biological effects of CDDLPS at the cellular level and can become the basis for the development of model test-systems for assessing the biological activity of drugs of this type.

\section{Materials and Methods}

Determination of molecular weight distribution was performed by the exclusive chromatography method (SPU 2.2.30) according to the following protocol and using following comparison solutions: bovine albumin (Sigma A7906), interferon alfa-2b (Pharmapark, Russia), human recombinant insulin (Eli Lilly, USA), octreotide acetate (BCN Peptides, Spain) were dissolved in the mobile phase at a solution concentration of $1 \mathrm{mg} / \mathrm{ml}$. Chromatography was performed using a liquid chromatograph Agilent1200, USA with a stainless steel column of $0.30 \times 7.8 \mathrm{~mm}$, filled with silica gel for exclusive chromatography with a particle size of $5 \mu \mathrm{m}$, pore diameter $125 \mathrm{~A}$; UV spectrophotometric detector at a wavelength of $254 \mathrm{~nm}$, and a flow rate of the mobile phase of $0.5 \mathrm{ml} / \mathrm{min}$. The calibration curve was built as follows: on the X-axis the values of $\ln$ of molecular weight were plotted, on the Y-axis the values of $\mathrm{ln}$ of the volume of contents were plotted, and the dependence graph was constructed using the fourth degree polynomial. The integration of the peaks was carried out to the baseline. The chromatographic system was considered suitable if the performance of the chromatographic column, calculated by the peak of the peptides, was not less than 3000 theoretical plates; the molecular weight of the peptides was less than 5000 [7].

Peptide mapping. To confirm the identity of the CDDLPS, samples were analyzed by the peptide mapping method according to SPU 2.2.55, using the method of enzymatic hydrolysis and trypsin Sigma T 6567 [7]. 
The amino acid composition was investigated according to SPU 2.2.56 using method 1 for hydrolysis of samples and method 4 with UV detection for amino acid analysis and the kit for amino acid analysis AccQ-FluorTM firm Waters (cat. No. WAT052880) according to the instructions of the manufacturer [7].

Cell culture. Studies were performed using in vitro models of human keratinocytes (HaCaT cell line), porcine endothelial cells (PAE cell line), bovine kidney cells (MDBK cell line), and mouse fibroblasts (3T3A31 cell line). Cell lines were obtained from the Bank of Cell Lines of Human and Animal Tissues of the RE Kavetsky Institute of Experimental Pathology, Oncology and Radiobiology NAS of Ukraine.

MDBK and 3T3A31 cells were cultured in DMEM medium (Biowest, France), supplemented with $10 \%$ newborn calf serum (NCS) (Biowest, France) or $10 \%$ fetal bovin serum (FBS) and $40 \mu \mathrm{g} / \mathrm{ml}$ gentamicin (Sigma, USA). HaCaT and PAE cell lines were cultured in RPMI 1640 medium (Biowest, France) with $10 \%$ FBS and $40 \mu \mathrm{g} / \mathrm{ml}$ gentamicin. The test cells were cultured in plastic dishes in a humidified atmosphere with $5 \% \mathrm{CO}_{2}$ at $37{ }^{\circ} \mathrm{C}$. The medium replacement and cell passage were performed according to the standard method [8]. For further studies, cells at the exponential growth phase were used.

Determination of proliferative and metabolic activity of cells by colorimetric methods. The proliferative and metabolic activities of the studied cells were evaluated by staining with crystal violet (assessment of total number of living cells by protein and DNA content) [9] or MTT (assessment of proliferative and metabolic activities of cells by their respiratory activity) [10]. 24 hours after the last passage, the test cells were seeded at a concentration of $1 \times 10^{4}$ cells/well in the wells of a 96-well plate (TPP, Italy) in complete DMEM/RPMI 1640 medium with different NCS/FBS content and $40 \mu \mathrm{g} / \mathrm{ml}$ gentamicin. Before seeding the cells, into the wells the CDDLPS at different concentrations was introduced. As a positive control for the analysis of cell proliferative and metabolic activities, the recombinant human epidermal growth factor (EGF) (Sigma, USA) was used. EGF was diluted in water for injection. Solutions of the concentrate and EGF were diluted to the working concentrations in DMEM or RPMI 1640 medium with appropriate FBS or NCS content (depending on the task of the experiment and the cells tested). Immediately after the introduction of the tested agents, the cells were placed in a $\mathrm{CO}_{2}$ incubator and cultured for another $24-72$ hours at $5 \% \mathrm{CO}_{2}$ and $37^{\circ} \mathrm{C}$. Upon completion of incubation with the agents, the proliferative and metabolic activity of the experimental cells was evaluated by colorimetric methods by staining the cells with crystal violet (1) (Sigma, USA) or MTT (2) (Applichem, Germany):

1. The medium was removed and $50 \mu \mathrm{l}$ of crystal violet solution $(5 \mathrm{mg} / \mathrm{ml}$ dye in $70 \%$ methyl alcohol) was added to each well. After 10 minutes the dye was washed three times with running water. The dye was extracted with $100 \mu \mathrm{l}$ per well of $96^{\circ}$ ethanol (Ukrmedspirt, Ukraine).

2. To each plate well, $10 \mu \mathrm{l}$ of MTT solution ( $5 \mathrm{mg} / \mathrm{ml}$ dye in physiologic saline) was added. Thereafter, the plate was incubated for 3 hours in a $\mathrm{CO}_{2}$ incubator at $37^{\circ} \mathrm{C}$. The medium was then removed from the wells and the formed tetraformazan crystals were dissolved in $50 \mu$ of dimethyl sulfoxide (Applichem, Germany).

When using crystal violet or MTT, the results were recorded using a multi-well spectrophotometer at an excitation wavelength of $540 \mathrm{~nm}$ (Labsystems Multiskan PLUS, Finland). The number of living cells was calculated by the formula: $X=\left(A_{540}\right.$ (experiment) $/ A_{540}$ (control) $) \times 100 \%$.

Determination of total protein content in the studied cells. MDBK cells were seeded at a concentration of $1 \times 10^{5}$ cells/well in 24-well plate (SPL, Korea) in DMEM medium with $4 \%$ NCS content and $40 \mu \mathrm{g} / \mathrm{ml}$ gentamicin. Immediately afterwards, the test CDDLPS was introduced in different concentrations into the corresponding wells of the plate. The test substance was diluted to working concentrations in DMEM medium with $4 \%$ NCS content. Immediately after the assay, cells were placed in a $\mathrm{CO}_{2}$ incubator and cultured for another 48 hours at $5 \% \mathrm{CO}_{2}$ and $37{ }^{\circ} \mathrm{C}$.

After incubation, the cells were removed from the substrate with a $0.02 \%$ solution of Versen (BioTestLaboratory, Ukraine), stained with trypan blue (HyClone, USA), and living and dead cells were counted using a hemocytometer (Farmmedtech, Ukraine).

The cell pellet was dissolved in $200 \mu \mathrm{l}$ of lysis buffer for protein isolation (Roche, Germany). The concentration of total protein in the cells was determined using a cuvette-free spectrophotometer (Nanodrop, Germany) according to the instructions of the device manufacturer. 
Analysis of cell distribution by cell cycle phases. After cell cultivation with a CDDLPS, the cell distribution by the cell cycle phases was determined using flow cytofluorimetry. MDBK cells were seeded in the wells of a 12-well plate (SPL, Korea) in DMEM medium with $4 \%$ NCS content and $40 \mu \mathrm{g} / \mathrm{ml}$ gentamicin $\left(1.5 \times 10^{5}\right.$ cells/well $)$. Immediately thereafter, the test drug was introduced into the appropriate wells at various concentrations. The test substance was diluted to working concentrations in DMEM with $4 \%$ NCS. Immediately after the assay, cells were placed in a $\mathrm{CO}_{2}$ incubator and cultured for another 48 hours at $5 \% \mathrm{CO}_{2}$ and $37^{\circ} \mathrm{C}$. After 2 days, the cells were removed from the substrate with a Versen solution, washed twice in phosphate-buffered saline (RAA, Austria). $200 \mu \mathrm{l}$ of cell suspension were mixed with $300 \mu 1$ Triton X100 (Sigma, USA), $10 \mu 1$ RNase $(50 \mu \mathrm{g} / \mathrm{ml})$ (Sigma, USA) and $25 \mu \mathrm{l}$ of propidium iodide $(50 \mu \mathrm{g} / \mathrm{ml})$ (Sigma, USA). Cells were incubated at $37^{\circ} \mathrm{C}$ for 10 minutes, followed by another 30 minutes at the room temperature in a dark place. The cells were then centrifuged and fixed in $200 \mu \mathrm{l}$ of a $1 \%$ paraformaldehyde solution (Sigma, USA). Cell cycle analysis was performed on a flow cytometer (FACScan, Becton Dickinson, USA) using appropriate software (ModFit, Becton Dickinson, USA).

Statistical analysis. Statistical processing of the obtained data was performed using the mathematical program for medical-biological statistics STATISTIS 6.0 using the Student's t-test; differences with a probability of at least $95 \%(p<0.05)$ were considered significant.

\section{Results and Discussion}

At the first stage of the study, the composition of the CDDLPS was investigated and standardized (Fig. 1).

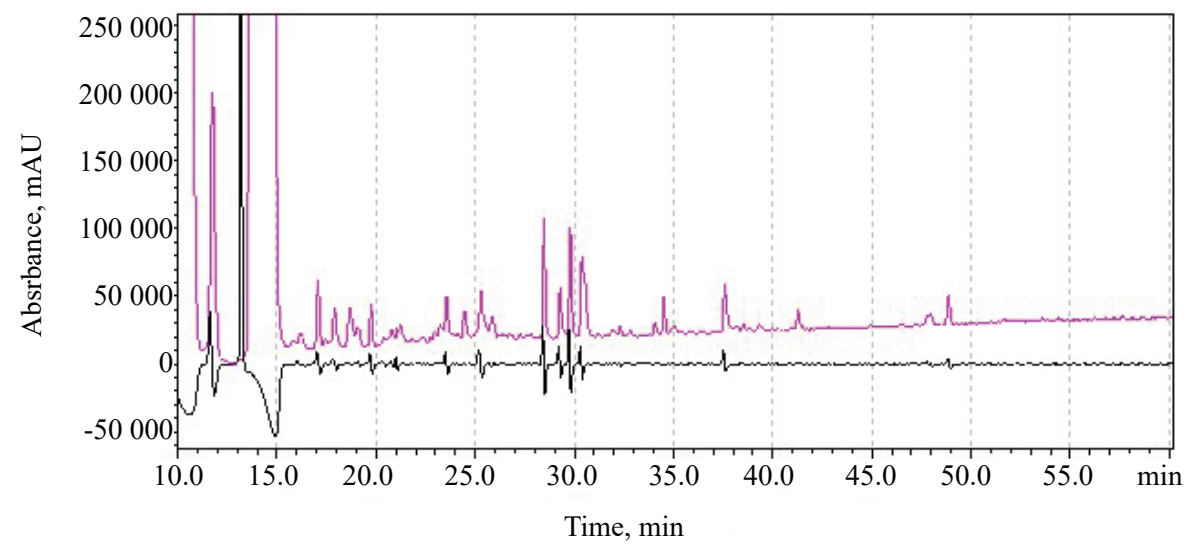

Fig. 1. Chromatogram of peptide mapping of the CDDLPS

Further analysis of the amino acid composition of the studied drug, the results of which are presented in Table 1, showed the highest percentage of such amino acids as glycine (16.93\%), alanine $(11.87 \%)$ and arginine $(9.71 \%)$. Each of these amino acids plays an important role in the processes of maintaining the body's homeostasis at the molecular and cellular levels. In particular, glycine in living cells synthesizes porphyrins and purine bases, alanine is an important participant in carbohydrate metabolism, and arginine is one of the key metabolites in the processes of nitrogen metabolism [11].

At the next stage, a series of studies were conducted, aimed at finding sensitive cellular systems and selecting adequate conditions for analyzing the effect of the test concentrate on the proliferative activity of mammalian cells. Cells of different tissues and organisms were used in the experiments. 4 types of cells of different histogenesis (human keratinocytes, porcine blood vessels, bovine kidneys, and mouse fibroblasts) were selected not only to determine the most sensitive test system for future assessment of the biological activity of the CDDLPS, but also for to select potential target cells.

The effect of the concentrate on the viability and proliferation of human keratinocytes of $\mathrm{HaCaT}$ cell line, porcine endothelium of PAE cell line, bovine kidney cells of MDBK line, and 
mouse fibroblasts of 3T3A31 cell line were investigated under standard cell culture conditions in complete medium. It was shown, that under these experimental conditions the CDDLPS did not significantly affect the proliferative activity of keratinocytes, endothelial cells and fibroblasts, but caused an increase of the number of living MDBK cells (by 7-10\%, compared with control cells) in most of the investigated concentrations (Table 2).

Table 1

Amino acid composition of the CDDLPS

\begin{tabular}{cc}
\hline Amino acid & Content, \% \\
\hline ASP & 3.13 \\
SER & 7.42 \\
GLU & 4.88 \\
GLY & 16.93 \\
HIS & 6.58 \\
NH3 & 0.00 \\
ARG & 9.71 \\
THR & 5.84 \\
ALA & 11.87 \\
PRO & 6.22 \\
CYS & 0.13 \\
TYR & 5.43 \\
VAL & 4.30 \\
MET & 1.40 \\
LYS & 4.33 \\
ILE & 2.01 \\
LEU & 5.35 \\
Phe & 4.46
\end{tabular}

Therefore, according to the results of the initial testing of the biological activity of the CDDLPS, it was found, that cells of the MDBK line were sensitive to the effect of the concentrate (by the assessment of their proliferative activity). Therefore, to study the mechanisms of action of the test concentrate in vitro and to develop a protocol for regular testing of the biological activity of this drug, our further attention was focused on MDBK cells.

Table 2

Evaluation of the CDDLPS effect on the viability and proliferation of mammalian cells in vitro

\begin{tabular}{ccccc}
\hline \multirow{2}{*}{$\begin{array}{c}\text { Concentration of the CD- } \\
\text { DLPS, } \boldsymbol{\mu g} / \mathbf{m l}\end{array}$} & \multicolumn{4}{c}{ Cell line } \\
\cline { 2 - 4 } & HaCaT & PAE & MDBK & 3T3A31 \\
\cline { 2 - 4 } 100 & $80.6 \pm 4.0$ & $88.2 \pm 2.5$ & $100.0 \pm 1.0$ & $97.2 \pm 4.4$ \\
50 & $77.0 \pm 8.2$ & $90.0 \pm 2.3$ & $109.0 \pm 0.6$ & $102.1 \pm 3.5$ \\
12.5 & $83.0 \pm 8.7$ & $90.8 \pm 1.9$ & $104.1 \pm 3.8$ & $100.5 \pm 0.5$ \\
2.5 & $93.2 \pm 6.8$ & $93.0 \pm 1.4$ & $108.6 \pm 1.2$ & $98.7 \pm 6.3$ \\
0.5 & $91.0 \pm 4.3$ & $92.1 \pm 1.2$ & $109.3 \pm 2.7$ & $100.0 \pm 5.9$ \\
0.1 & $95.4 \pm 7.0$ & $92.4 \pm 2.9$ & $109.2 \pm 1.0$ & $96.4 \pm 3.0$ \\
0.02 & $90.1 \pm 3.6$ & $95.2 \pm 0.2$ & $112.5 \pm 2.2$ & $101.8 \pm 4.2$
\end{tabular}

Note: * - compared to cells of the control group, which were cultured with physiologic solution (100\%). Cells were cultured in the presence of the CDDLPS in medium with $10 \%$ FBS/NCS for 48 hours. The results were calculated after staining with crystal violet.

In order to increase the sensitivity of such a system and reduce the effect of other biologically active substances, in particular growth factors, on the proliferative activity of MDBK cells, at the 
following stage of the research we have assessed the effect of the CDDLPS on the cells, provided their cultivation in medium without NCS or with low NCS content $(2 \%, 4 \%)$.

The obtained results show that under conditions of $0 \%$ serum content in the medium, the concentrate does not affect the proliferation of MDBK cells (Table 3). However, increasing the percentage of NCS in the medium to $2 \%$ led to an increase in the number of living MDBK cells after treatment with the CDDLPS by 7-20\%, compared with control cells (Table 3). Treatment of cells with the CDDLPS in medium with $4 \%$ NCS content was accompanied by an increase in the number of living cells by 10-25\%, compared with the control (Table 3).

Table 3

Evaluation of the CDDLPS effect on MDBK cells in vitro provided their cultivation in medium with low serum content

\begin{tabular}{|c|c|c|c|}
\hline \multirow{3}{*}{ Concentration of the CDDLPS, $\mu \mathrm{g} / \mathrm{ml}$} & \multicolumn{3}{|c|}{ NCS content, $\%$} \\
\hline & $\mathbf{0}$ & 2 & 4 \\
\hline & \multicolumn{3}{|c|}{ Number of living cells, \% * } \\
\hline 100 & $95.5 \pm 4.9$ & $105.2 \pm 2.3$ & $121.4 \pm 4.0$ \\
\hline 50 & $97.4 \pm 3.5$ & $114.0 \pm 3.3$ & $112.7 \pm 2.4$ \\
\hline 12.5 & $96.7 \pm 7.6$ & $119.8 \pm 1.1$ & $115.2 \pm 2.0$ \\
\hline 2.5 & $92.5 \pm 5.4$ & $117.4 \pm 3.5$ & $121.8 \pm 3.4$ \\
\hline 0.5 & $93.1 \pm 5.2$ & $114.3 \pm 3.7$ & $116.8 \pm 2.1$ \\
\hline 0.1 & $98.3 \pm 2.2$ & $113.3 \pm 1.5$ & $111.0 \pm 2.5$ \\
\hline 0.02 & $96.4 \pm 1.8$ & $109.5 \pm 2.0$ & $119.5 \pm 4.0$ \\
\hline
\end{tabular}

Note: * - compared to cells of the control group, which were cultured with physiologic solution (100\%). Cells were cultured in the presence of the CDDLPS for 48 hours. The results were calculated after staining with crystal violet.

The results suggest that the CDDLPS cannot completely replace such a source of nutrients as serum, but enhances metabolic and biosynthetic processes in MDBK cells, accompanied by an increase in their proliferative activity. Such changes also indicate that the concentrate may activate the self resources of cells.

In addition, it becomes clear that by reducing the NCS content, which is the source of proteins, carbohydrates, hormones, growth factors and cytokines, lipids and fatty acids, vitamins and trace elements, it is possible to increase the sensitivity of the cellular test system to assess the biological activity of CDDLPS. Against the background of low NCS content, the effect of the concentrate-dependent stimulation of cell proliferation is more pronounced (Table 3). Therefore, these experimental conditions (4\% NCS) are the most optimal for regular testing of the biological activity of this agent.

Taking into account the obtained results, all further studies were performed using a medium with $4 \%$ NCS content.

Another important factor that significantly affects the cell culture behavior in vitro is the duration of incubation. In order to optimize the conditions for testing the biological activity of the concentrate on MDBK cell model and to determine the dynamics of changes in the metabolic and proliferative activity of the cells after their treatment with the experimental agent, we investigated the effect of the CDDLPS on the number of living cells after 24, 48 and 72 hours of incubation.

After 24 hours of incubation of cells with the CDDLPS, we did not observe significant changes in their number, compared with the control (Table 4). The highest rates of proliferative activity of MDBK cells were recorded after 48 hours of incubation of the cells with the concentrate. The number of living cells increased by 10-25\%, compared with the control (Table 4). After 72 hours of incubation of the cells with the experimental drug, there was registered a decrease in the proliferative effects of the concentrate, compared to the 48 hours data, and an increase in the number of MDBK cells by only 7-12\% (compared to the control cells) in several of the tested CDDLPS concentrations (Table 4).

The data obtained indicate that the most potent manifestations of the biological effects of the concentrate in the in vitro system are realized after 2 days of incubation of MDBK cells in the 
presence of the drug, and this incubation period of cells with the CDDLPS should be used in the test system for regular evaluation of its biological activity.

Table 4

Effect of duration of incubation of MDBK cells with the CDDLPS on the number of living cells

\begin{tabular}{cccc}
\hline \multirow{2}{*}{ Concentration of the CDDLPS, $\boldsymbol{\mu g} / \mathbf{m l}$} & \multicolumn{2}{c}{ Duration of incubation of MDBK cells with the CDDLPS } \\
\cline { 2 - 3 } & $\mathbf{2 4}$ hours & $\mathbf{4 8}$ hours & $\mathbf{7 2}$ hours \\
\cline { 2 - 3 } & & Number of living cells, \% * \\
\hline 100 & $102.6 \pm 4.8$ & $121.4 \pm 4.0$ & $114.8 \pm 3.4$ \\
50 & $104.0 \pm 3.4$ & $112.7 \pm 2.4$ & $104.0 \pm 5.8$ \\
12.5 & $101.6 \pm 5.7$ & $115.2 \pm 2.0$ & $102.8 \pm 1.0$ \\
2.5 & $97.0 \pm 1.4$ & $121.8 \pm 3.4$ & $116.2 \pm 4.4$ \\
0.5 & $105.0 \pm 2.5$ & $116.8 \pm 2.1$ & $107.3 \pm 2.0$ \\
0.1 & $100.0 \pm 3.5$ & $111.0 \pm 2.5$ & $104.7 \pm 4.6$ \\
0.02 & $98.0 \pm 3.0$ & $119.5 \pm 4.0$ & $112.5 \pm 5.2$
\end{tabular}

Note: *-compared to cells of the control group, which were cultured with physiologic solution (100\%). The results were calculated after staining with crystal violet.

The absence of a linear dependence between the concentration of the CDDLPS and the number of living MDBK cells indicates the different mechanisms of its action and, accordingly, its biological effects, dependent on the dose. Therefore, in order to study the peculiarities of the mechanism of action of different concentrations of the drug, at the next stage of our study we conducted a comparative analysis of the number of living MDBK cells after their treatment with a concentrate under different conditions of visualization of the obtained results:

1) by staining the cells with crystal violet, which stains DNA and proteins in the cells;

2) in the MTT test, where the respiratory activity of living cells is recorded.

In addition, since the CDDLPS is a new unique regenerating agent and so far, there are none standardized formulations of comparison for its mechanism of action, therefore, the effect of the concentrate on cell proliferation has been evaluated in comparison with EGF, which may be considered similar by its biological effects.

The obtained results indicate that when determining the biological activity of the concentrate and EGF by the amount of protein and DNA in MDBK cells, both drugs at the tested concentrations cause an increase in extinction rates by $10-35 \%$ and $7-25 \%$, respectively, compared with control cells (Table 5, Fig. 2). There was no statistically significant difference between the number of living cells in these two experimental groups.

The comparative analysis of the respiratory activity of MDBK cells after their treatment with the concentrate or EGF showed that in most of the tested concentrations, EGF more effectively stimulated the respiratory activity of the tested cells and the extinction level in the MTT-test was by 10-25\% higher than in the control group (Table 6). However, treatment of cells with the concentrate led to an increase in extinction rates by $7-19 \%$, compared with control, only in three of the tested concentrations of the drug $(100 \mu \mathrm{g} / \mathrm{ml}, 50 \mu \mathrm{g} / \mathrm{ml}, 50 \mathrm{ng} / \mathrm{ml})$.

The results obtained suggest that EGF at the tested concentrations stimulates the proliferative activity of MDBK cells, which is expressed in an increase in the amount of DNA, proteins (7-25\%) and increased respiratory activity of cells (10-25\%). At the same time, the CDDLPS stimulates the synthesis of DNA and proteins at all tested concentrations, and enhances the respiratory activity of cells in just a few ones. Such data may testify that depending on its concentration CDDLPS enhances the biosynthetic or respiratory activity of the investigated cells, which indicates the activation of not only proliferative, but also metabolic activity of MDBK cells. Based on the data obtained, it can be concluded, that crystal violet should be used to visualize and calculate the results of the biological activity of the concentrate in a sensitive cellular test system.

To test this hypothesis, regarding the mechanisms of realization of the biological activity of the concentrate, we have determined the amount of total protein in MDBK cells after their cultivation with the test substance. 
Table 5

Comparative analysis of the effect of the CDDLPS and EGF on the number of living MDBK cells in vitro. The results were calculated after staining with crystal violet

\begin{tabular}{ccc}
\hline \multirow{2}{*}{ Concentration of agents } & \multicolumn{3}{c}{ Number of living cells, \% * } \\
\cline { 2 - 3 } & CDDLPS & EGF \\
\hline $100 \mu \mathrm{g} / \mathrm{ml}$ & $121.4 \pm 4.0$ & $117.8 \pm 2.4$ \\
$50 \mu \mathrm{g} / \mathrm{ml}$ & $119.7 \pm 3.4$ & $120.3 \pm 4.0$ \\
$25 \mu \mathrm{g} / \mathrm{ml}$ & $109.0 \pm 7.0$ & $118.0 \pm 1.8$ \\
$12.5 \mu \mathrm{g} / \mathrm{ml}$ & $113.2 \pm 2.3$ & $111.4 \pm 3.5$ \\
$6.2 \mu \mathrm{g} / \mathrm{ml}$ & $110.7 \pm 6.0$ & $103.2 \pm 5.8$ \\
$3.1 \mu \mathrm{g} / \mathrm{ml}$ & $130.6 \pm 4.5$ & $113.0 \pm 4.6$ \\
$1.6 \mu \mathrm{g} / \mathrm{ml}$ & $113.0 \pm 4.4$ & $111.2 \pm 4.4$ \\
$0.8 \mu \mathrm{g} / \mathrm{ml}$ & $113.2 \pm 3.4$ & $113.8 \pm 7.8$ \\
$50 \mathrm{ng} / \mathrm{ml}$ & $116.8 \pm 6.4$ & $109.7 \pm 7.7$
\end{tabular}

Note: *-compared to cells of the control group, which were cultured with physiologic solution (100\%). The cells were cultured with the CDDLPS for 48 hours

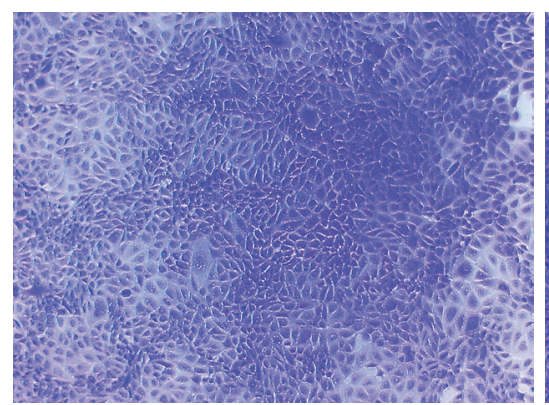

$a$

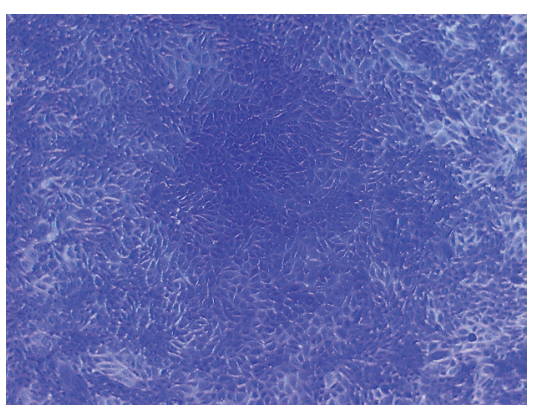

$b$

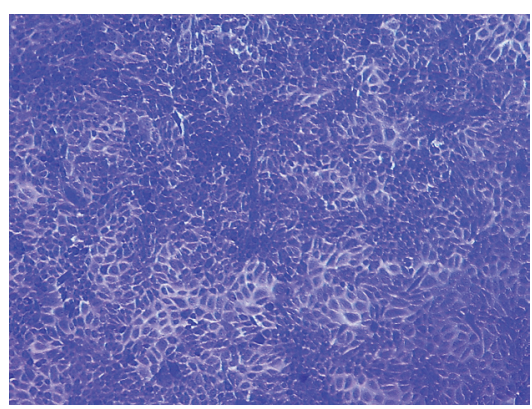

c

Fig. 2. MDBK cells are treated with the CDDLPS or EGF and stained with crystal viole: $a$ - MDBK control, $b$ - MDBK+CDDLPS $50 \mu \mathrm{g} / \mathrm{ml}$. $c$ - MDBK+EGF $50 \mu \mathrm{g} / \mathrm{ml}$. Control - cells cultured with physiologic saline. Cells were cultured with the CDDLPS or EGF for 48 hours in medium with $4 \%$ NCS

Table 6

Comparative analysis of the effect of the CDDLPS and EGF on the number of live MDBK cells in vitro. The results were calculated in MTT-test

\begin{tabular}{ccc}
\hline \multirow{2}{*}{ Concentration of agents } & Number of living cells, \% * & EGF \\
\cline { 2 - 3 } & CDDLPS & $113.8 \pm 1.5$ \\
\hline $100 \mu \mathrm{g} / \mathrm{ml}$ & $116.4 \pm 2.7$ & $116.1 \pm 2.9$ \\
$50 \mu \mathrm{g} / \mathrm{ml}$ & $110.7 \pm 3.7$ & $110.4 \pm 0.9$ \\
$25 \mu \mathrm{g} / \mathrm{ml}$ & $106.0 \pm 1.4$ & $112.1 \pm 1.6$ \\
$12.5 \mu \mathrm{g} / \mathrm{ml}$ & $100.2 \pm 2.1$ & $101.6 \pm 3.6$ \\
$6.2 \mu \mathrm{g} / \mathrm{ml}$ & $100.3 \pm 3.8$ & $115.3 \pm 0.7$ \\
$3.1 \mu \mathrm{g} / \mathrm{ml}$ & $107.4 \pm 1.9$ & $120.0 \pm 6.4$ \\
$1.6 \mu \mathrm{g} / \mathrm{ml}$ & $98.0 \pm 3.6$ & $104.1 \pm 3.2$ \\
$0.8 \mu \mathrm{g} / \mathrm{ml}$ & $99.2 \pm 2.0$ & $112.5 \pm 1.8$
\end{tabular}

Note: *-compared to cells of the control group, which were cultured with physiologic solution (100\%). The cells were cultured with the CDDLPS for 48 hours

It was found, that the concentrate statistically significantly increased the total content of protein in MDBK cells by 20-40\%, compared with the control (Fig. 3). It should be noted, that such changes are dose-dependent. Thus, higher concentrations of the experimental drug $(100-50 \mu \mathrm{g} / \mathrm{ml})$ 
caused an increase in the protein content of the cells by an average of 40-45\%, compared with the control. However, lower concentrations of the concentrate $(1.5 \mu \mathrm{g} / \mathrm{ml}-50 \mathrm{ng} / \mathrm{ml})$ led to an increase of protein content in MDBK cells by 20-25\%, compared with the control. Therefore, it can be concluded, that the CDDLPS stimulates biosynthetic processes in the studied cells, in particular protein synthesis. The obtained results correlate with the data, presented above, since crystal violet in cells binds specifically to protein molecules and to DNA molecules.

It should be noted, that, in our opinion, such analysis can also be used as a sensitive cellular test system for regular testing of the biological activity of the concentrate.

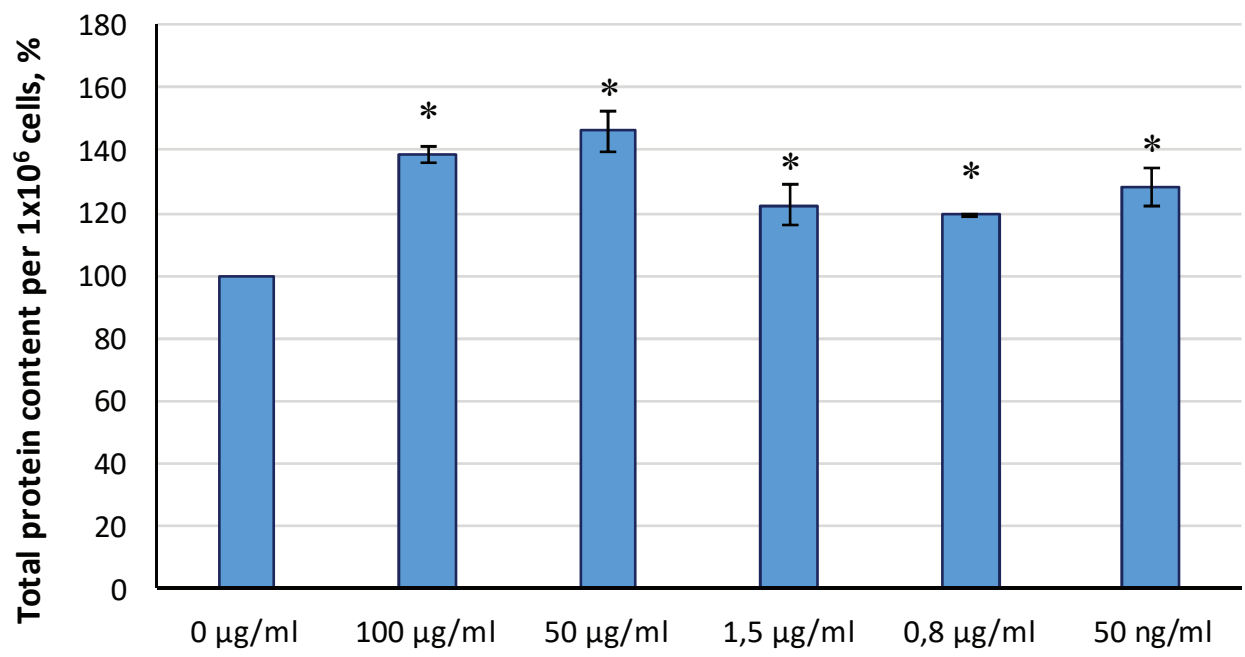

\section{Concentration of the studied substance}

Fig. 3. Changes of total protein content in MDBK cells after their treatment with the CDDLPS. Control $(0 \mu \mathrm{g} / \mathrm{ml})$ - cells, cultured with physiologic saline. Cells were cultured in the presence of the concentrate for 48 hours in medium with $4 \% \mathrm{NCS}$. Note: * - the defference is significant, compared to the control group, $p<0.05$

In order to find possible mechanisms of action of the concentrate, the effect of its various concentrations on the distribution of MDBK cells by cell cycle phases was also investigated.

Table 7

Influence of the CDDLPS on the distribution of MDBK cells by phases of the mitotic cycle

\begin{tabular}{cccc}
\hline \multirow{2}{*}{ Experimental groups } & \multicolumn{3}{c}{ Cell cycle phases, \% } \\
\cline { 2 - 4 } & $\boldsymbol{G}_{\mathbf{0}} / \boldsymbol{G}_{\mathbf{1}}$ & $\boldsymbol{S}$ & $\boldsymbol{G}_{\mathbf{2}} / \boldsymbol{M}$ \\
\hline MDBK, control & $63.3 \pm 1.4$ & $15.2 \pm 0.4$ & $21.5 \pm 1.8$ \\
MDBK+CDDLPS, $100 \mu \mathrm{g} / \mathrm{ml}$ & $64.2 \pm 5.9$ & $15.0 \pm 4.2$ & $20.8 \pm 1.6$ \\
MDBK+CDDLPS, $50 \mu \mathrm{g} / \mathrm{ml}$ & $59.6 \pm 0.9$ & $14.5 \pm 2.6$ & $25.9 \pm 3.5$ \\
MDBK+CDDLPS, $3 \mu \mathrm{g} / \mathrm{ml}$ & $53.2 \pm 5.4$ & $14.9 \pm 6.2$ & $31.9 \pm 0.6^{*}$ \\
MDBK+CDDLPS, $1,5 \mu \mathrm{g} / \mathrm{ml}$ & $59.5 \pm 2.2$ & $15.1 \pm 1.2$ & $25.4 \pm 2.0$ \\
MDBK+CDDLPS, $50 \mathrm{ng} / \mathrm{ml}$ & $58.3 \pm 3.4$ & $26.4 \pm 1.4^{*}$ & $15.3 \pm 1.0^{*}$
\end{tabular}

*Note: statistically significant differences, compared to the cells of the control group, $p<0.05$. Control-the cells, cultured with physiologic solution. The cells were cultured with the CDDLPS for 48 hours in medium with $4 \%$ NCS.

The obtained results showed that the experimental drug at a concentration of $3 \mu \mathrm{g} / \mathrm{ml}$ leads to a minor, but statistically significant increase in the number of cells in the G2/M phase of the cell cycle by $10 \%$, compared with the control, indicating a higher proliferative activity of MDBK cells in this group (Table 7, Fig. 4, b). However, in the group, where cells were cultured in the presence of $50 \mathrm{ng} / \mathrm{ml}$ CDDLPS, a cell cycle delay was observed at the synthetic phase (S phase) of the mitotic cycle with a consequent decrease of the number of proliferating cells (G2/M phase) (Table 7, Fig. 4, c). 


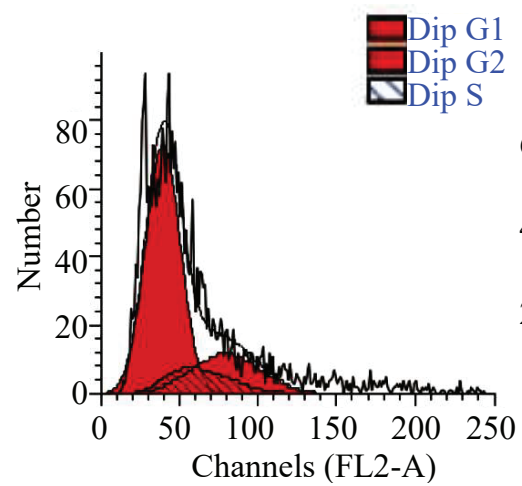

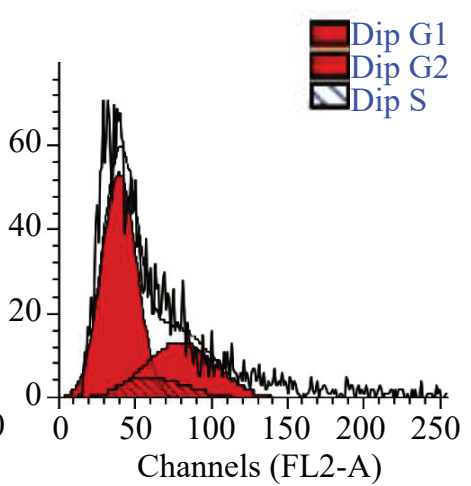

$b$

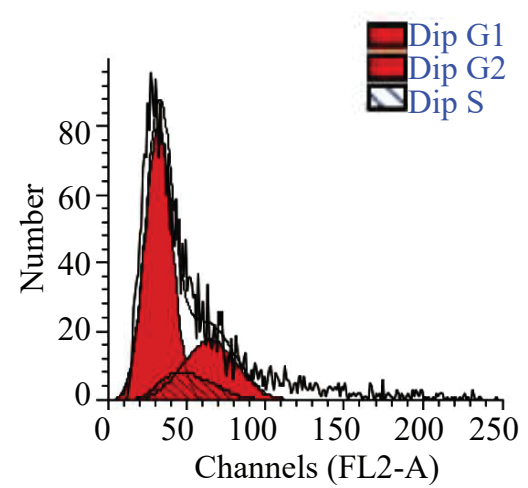

C

Fig. 4. Diagrams of distribution of MDBK cells by the cell cycle phases after their treatment with the CDDLPS: $a$-MDBK control, $b-\mathrm{MDBK}+\mathrm{CDDLPS} 3 \mu \mathrm{g} / \mathrm{ml}, c-\mathrm{MDBK}+\mathrm{CDDLPS} 50 \mathrm{ng} / \mathrm{ml}$

The obtained results confirm our assumptions about the differently directed mechanisms of action of the test substance, depending on its concentration. It is clear that, depending on the dose, the CDDLPS significantly enhances biosynthetic processes in cells and stimulates proliferation of MDBK cells, which correlates with the above data.

Study limitation.

1) One cell line (MDBK) of all studied was quite sensitive to the biological effects of the test substance. However, this cell line is often used for study in various fields of biology and is available to researchers.

2) In determining the amount of total protein in the test cells, it is important to carefully calculate the number of cells in the samples before the protein isolation. This problem can be solved by increasing the number of indicator counts at one point.

Prospects for further research.

The obtained results can become the basis for a more detailed and complete study of the CDDLPS mechanisms of action at the cellular and molecular levels. Also, the sensitive cell model and methods, described above, can be used to study the biological effects of drugs of this class in vitro.

\section{Conclusions}

The cells of the bovine kidney of MDBK cell line were found to be sensitive to the effect of the CDDLPS, as estimated by the proliferative activity of the cells. The concentrate enhances metabolic and biosynthetic processes in MDBK cells, in particular protein synthesis, accompanied by an increase of their proliferative activity. The obtained results suggest that, depending on the concentration of the CDDLPS, first of all, this substance enhances the biosynthetic and metabolic activity of the investigated cells and in only a few concentrations increases their proliferation. Herewith, the concentrate may activate the self resources of cells.

In addition, on the basis of the obtained data we have developed a sensitive cell test system and protocol for regular testing of the biological activity of the CDDLPS. According to the developed protocol, an in vitro assessment of the biological activity of the concentrate using model MDBK cells should be performed under the following conditions: a medium with $4 \%$ NCS content, and duration of cell incubation with the concentrate for 48 hours. The most sensitive colorimetric method of visualization of the results is estimation of viability and proliferative activity of the cells by their staining with crystal violet. After exposure of MDBK cells to the CDDLPS under the above conditions of cultivation, a method of estimating the total protein content can be used as an additional method for calculating the results of the biological activity of the concentrate.

\section{Acknowledgments}

The studies were conducted with the financial support of JSC «Farmak». 


\section{References}

[1] Borena, B. M., Martens, A., Broeckx, S. Y., Meyer, E., Chiers, K., Duchateau, L., Spaas, J. H. (2015). Regenerative Skin Wound Healing in Mammals: State-of-the-Art on Growth Factor and Stem Cell Based Treatments. Cellular Physiology and Biochemistry, 36 (1), 1-23. doi: https://doi.org/10.1159/000374049

[2] Gurtner, G. C., Werner, S., Barrandon, Y., Longaker, M. T. (2008). Wound repair and regeneration. Nature, 453 (7193), $314-321$. doi: https://doi.org/10.1038/nature07039

[3] Shen, C., Sun, L., Zhu, N., Qi, F. (2017). Kindlin-1 contributes to EGF-induced re-epithelialization in skin wound healing. International Journal of Molecular Medicine, 39 (4), 949-959. doi: https://doi.org/10.3892/ijmm.2017.2911

[4] Choi, J. S., Leong, K. W., Yoo, H. S. (2008). In vivo wound healing of diabetic ulcers using electrospun nanofibers immobilized with human epidermal growth factor (EGF). Biomaterials, 29 (5), 587-596. doi: https://doi.org/10.1016/j.biomaterials.2007.10.012

[5] Berlanga-Acosta, J., Gavilondo-Cowley, J., López-Saura, P., González-López, T., Castro-Santana, M. D., López-Mola, E. et. al. (2009). Epidermal growth factor in clinical practice - a review of its biological actions, clinical indications and safety implications. International Wound Journal, 6 (5), 331-346. doi: https://doi.org/10.1111/j.1742-481x.2009.00622.x

[6] Bodnar, R. J. (2013). Epidermal Growth Factor and Epidermal Growth Factor Receptor: The Yin and Yang in the Treatment of Cutaneous Wounds and Cancer. Advances in Wound Care, 2 (1), 24-29. doi: https://doi.org/10.1089/wound.2011.0326

[7] State Pharmacopoeia of Ukraine (2015). State Enterprise "Ukrainian Scientific Pharmacopoeial Center for Medicinal Products Quality”. Vol. 1. Kharkiv: State Enterprise "Ukrainian Scientific Pharmacopoeial Center for Medicinal Products Quality”, 128. Available at: https://docplayer.net/77551242-Derzhavna-farmakopeya-ukrayini.html

[8] Freshney, R. I. (2016). Culture of animal cells: A manual of basic technique and specialized applications. John Wiley \& Sons, 728.

[9] Vega-Avila, E., Pugsley, M. K. (2011). An overview of colorimetric assay methods used to assess survival or proliferation of mammalian cells. Proc West Pharmacol Soc, 54, 10-14.

[10] Präbst, K., Engelhardt, H., Ringgeler, S., Hübner, H. (2017). Basic Colorimetric Proliferation Assays: MTT, WST, and Resazurin. Cell Viability Assays, 1-17. doi: https://doi.org/10.1007/978-1-4939-6960-9_1

[11] Wu, G. (2010). Functional Amino Acids in Growth, Reproduction, and Health. Advances in Nutrition, 1 (1), 31-37. doi: https:// doi.org/10.3945/an.110.1008 